\title{
A feasibility study on identification of Basmati (aromatic) rice using SAR data
}

\author{
VArunika Jain*, C Patnaik and S Panigrahy \\ EPSA, Space Applications Centre, Ahmedabad, India. \\ ${ }^{*}$ Corresponding author.e-mail: varunika@sac.isro.gov.in
}

Rice areas in India are being mapped for acreage estimation using Synthetic Aperture Radar (SAR) data under forecasting agricultural output using space, agrometeorology and land-based observations (FASAL) program for over a decade now. Under this study, an attempt was made to segregate rice areas based on variety in parts of Punjab state. Data acquisition was done at critical stages of rice growth. The shift in transplantation in temporal domain and difference in canopy volume formed the basis of characterization of rice crop into two different varieties namely aromatic and non-aromatic. Multitemporal $\mathrm{HH}$ polarization data along with rate of change of cross polarization ratio $(\mathrm{HH} / \mathrm{HV})$ from July to September 2011 was used. The aromatic rice could be separated from normal rice with 91\% accuracy.

\section{Introduction}

The operational rice area estimation is in progress in India; however, the varietal differences can be indicative of the differences in the fluxes emanated and can also help in economic planning. Rice contributes in a great way to the methane emission. Further, the areas where the crop is present for a longer duration can be monitored and appropriate guidelines can be generated for the study of various parameters of the fields occupied. This study is an attempt to monitor varieties of rice at an early stage so that the spatial extent can be mapped and the contribution of the crop towards the various fluxes can be estimated.

The potential of multitemporal Synthetic Aperture Radar (SAR) data for rice crop monitoring has been demonstrated by a number of investigators (Saich and Borgeaud 2000). Multitemporal data is more suitable for crop monitoring and condition assessment, as changes and variations in crop growth can be observed and information on crop growth and condition can be extracted. The lowland cultural practice is the most dominant one in India/Asia. These are further classified as rainfed shallow, intermediate, deep, and irrigated (De Dutta 1981; Huke 1982). The results indicated that all wetland systems show a typical and unique temporal signature of radar backscatter, which can be used to identify the rice fields (Chakraborty et al. 1997). It also indicated that data acquisition at critical crop growth stages is an essential requirement to obtain desired classification accuracy. It was also feasible to separate rice subclasses based on its growth stages with high levels of accuracy.

\section{Study area and data used}

The aromatic rice (locally called Basmati) growing districts of Punjab like Amritsar, Hoshiarpur, Gurdaspur, Patiala, and Taran Taran were used as study area. Radarsat-2 C-band ScanSAR narrow

Keywords. SAR; backscatter; aromatic rice; cross-polarization ratio; radiative transfer. 
Table 1. Specifications of Radarsat-2 SAR data used.

\begin{tabular}{ll}
\hline Beam position & ScanSAR narrow B \\
Data type & 16 bits \\
Beam mode & Descending \\
Incidence angle range & $31-46$ (degrees) \\
Polarisation & $\mathrm{HH}, \mathrm{HV}$ \\
Pixel spacing & $25 \mathrm{~m}$ \\
Product type & $\mathrm{SGF}$ \\
Swath & $300 \mathrm{~km}$ \\
\hline
\end{tabular}

B Synthetic Aperture Radar (SAR) data obtained in $\mathrm{HH}$ and $\mathrm{HV}$ polarizations was used. Four date data acquired on June 22, July 16, August 9, and October 20, 2011 were used. Along with 2011 data, 12 September and 6 October, 2009 data were used to confirm the traditional nonaromatic rice areas. Table 1 highlights the details of data acquired.

Ground truth data was collected in the area; crop parameters like age, height, number of plants $/ \mathrm{m}^{2}$, number of tillers/plant, crop condition, variety, and field parameters like field condition, water depth, and bund height were recorded. A GPS was used to locate the sites. The knowledge base, on which the decision rules for the current season are framed, is derived from ground truth.

\section{Methodology}

\subsection{Dataset preparation}

The processing of multitemporal Radarsat- 2 data for this study involved: (i) data download; (ii) speckle reduction; (iii) data calibration; (iv) image georeferencing, and (v) multidate image data coregistration. The processing was done using Geomatica ver. 9.1.

The acquired SAR data was in 16-bit in .tiff format. The image data along with the ephemeris data containing the ground control points and the calibration gain values were downloaded and stored in the native format. Speckle was suppressed using Enhanced Lee Filter with window size $5 * 5$ and number of looks 2.

After suppressing the speckle by filtering, the gain scaling values provided across the range were used for converting the data into a backscatter image in $\mathrm{dB}$ domain. This process of calibration, resulted in $\sigma^{\circ}$ image in $\mathrm{dB}$ domain where the featurewise backscatter could be quantified. This $\mathrm{dB}$ image is in 32-bit real format. The equation used for calibration is as follows:

$$
\sigma^{\circ}(\text { in } \mathrm{dB})=10 * \log _{10}\left(\left(D N^{2}+A_{0}\right) / A_{j}\right)
$$

where $D N$ is the amplitude value from the raw data, $A_{0}$ is the offset value, usually 0 and $A_{j}$ is the gain scaling coefficient.

The calibrated data need to be stacked together to generate multitemporal data for use in the study. The output coregistered and georectified image contained the four multitemporal data at 25-m pixel spacing. A second order polynomial with cubic convolution resampling was adopted for this.

\subsection{Classification}

Rice is the predominant crop grown in the study area. Clusters of rice growing areas were observed in the multidate SAR image. Rice crop is traditionally transplanted during the month of June. Its duration is 120 days and it is harvested by first week of October. Aromatic or basmati rice is transplanted during mid July and being a long duration crop of about 150 days, it is harvested by the first week of November. Hierarchical knowledge based decision rule classifier was used to classify the rice and non-rice areas. Here, the knowledge can be heuristic, i.e., based on experience and reasoning. It uses a logical (near constant temporal backscatter of water, urban, forest; canopy backscatter based on soil contributions as well as volume scattering) and a mathematical approach. The decisionrule classifier has been developed based on a radiative transfer (RT) model and calibrated using large number of rice sites in India, and controlled field experiments. This procedure accounts for change in backscatter as a result of transplanting of rice and crop (biomass) growth in multi-date data to classify rice areas. Ban and Howarth (1999), also used masking techniques for crop classification. The typical temporal behaviour (i.e., crop phenology and flood condition of rice field), the resulting dominant interaction mechanisms (SAR signal-vegetationwater), and the corresponding backscattering coefficient (the RT model) were the basis of the knowledge base.

Even under the non-ideal condition of fluctuating water levels, the growth pattern is unique to identify rice fields from multitemporal SAR signatures alone. Thus, SAR data acquired during transplanting/establishment stage, tillering stage, and peak vegetative stage has been found suitable for accurate identification of rice crop.

\subsection{Discrimination of aromatic rice}

The SAR data acquisitions were planned to coincide with the different stages of the rice crop. The transplantation, tillering, early vegetative, and hard dough stages were covered by 2011 datasets 
and data of 2009 was used to account for flowering, milking, and soft dough stages. The study area is a traditional basmati rice growing area. The data acquisition in 2009 had a shift of 10 days as compared to 2011, i.e., the acquisitions were 10 days earlier than what would have been for year 2011 . However, in 2009 the vagaries of rainfall caused a shift in the transplantation of rice by about a week, which sufficed for the 10 days' shift observed in the data. In spite of this the backscatter from rice and other pseudo invariant targets were studied and it was observed that no significant variations in the backscatter were obtained across the years. Therefore date normalization was not required for 2009 data. The classification was carried out using contiguous datasets of 2011 and 2009. Secondly, it has been observed over a period of time that due to the standing water conditions and the canopy growth over a period of acquisitions, the rice signatures are nearly static.

The typical increasing trend of backscatter values pertaining to transplantation and to flowering stages was used to classify rice in multitemporal HH data. Therefore October data was not used while forming decision rules. An attempt was made to model the changes in backscatter due to increasing canopy volume with age of the crop in multitemporal HV data. Cross polarization ratio (XPR) $(\mathrm{HH} / \mathrm{HV})$ was used to address the volume component of rice canopy at later stages. Rate of change (RoC) of XPR was calculated for each set of consecutive dates' datasets. Using these XPR values rice areas could still not be classified distinctively. Hence rate of change of XPR from July to September was calculated and used in the model. It specified the amount of change in canopy volume from transplantation to flowering stage. The complete model used is as follows:

$-12 \mathrm{~dB}<\mathrm{D} 1<-4.5 \mathrm{~dB},-17 \mathrm{~dB}<\mathrm{D} 2<-9.5 \mathrm{~dB}$, $-10 \mathrm{~dB}<\mathrm{D} 3<-5 \mathrm{~dB},-10.5 \mathrm{~dB}<\mathrm{D} 4<-7.5 \mathrm{~dB}$, $-13.50 \mathrm{~dB}<\operatorname{RoC}(\mathrm{XPR})<5 \mathrm{~dB}$

The pseudo code given here is indicative of the rice signatures obtained from the dataset over parts


Figure 1. FCC comprising (a) June, July, August data, and (b) July, August, September data.

Table 2. Summary of features of basmati vs. non-Basmati rice as observed during ground truth (GT) in July and October.

\begin{tabular}{|c|c|c|c|c|c|}
\hline \multirow[b]{2}{*}{ Sl. no. } & \multirow[b]{2}{*}{ Feature } & \multicolumn{2}{|c|}{ Basmati } & \multicolumn{2}{|c|}{ Non-basmati } \\
\hline & & $\overline{\mathrm{GT}}-$ July 24 & GT - October 15 & $\overline{\text { GT }- \text { July } 24}$ & GT - October 15 \\
\hline 1 & Date of transplanting & \multicolumn{2}{|c|}{ July $5-10$} & \multicolumn{2}{|c|}{ June $20-25$} \\
\hline 2 & Crop stage & Seedling & Soft dough & Tillering & Maturity \\
\hline 3 & Plant height & $15-20 \mathrm{~cm}$ & $100-110 \mathrm{~cm}$ & $40-45 \mathrm{~cm}$ & $125-135 \mathrm{~cm}$ \\
\hline 4 & Plants/m2 & $18-20$ & $18-20$ & $18-20$ & $18-20$ \\
\hline 5 & Tillers/hill & $12-14$ & $12-4$ & $16-18$ & $16-18$ \\
\hline 6 & Crop condition & \multicolumn{2}{|c|}{ Good } & \multicolumn{2}{|c|}{ Good } \\
\hline 7 & Backscatter in $\mathrm{dB}$ & -17.11 & -7.66 & -14.46 & -5.9 \\
\hline
\end{tabular}


of Punjab. Adequate ground truth information was collected synchronous with the passes of the satellite. The crop parameters along with the field parameters like water depth, extent of site, bund utilisation, etc., were collected. From the total 28 ground truth sites collected, 8 sites were kept aside to verify the classification. The data from 20 sites were used to generate the decision rules. The methodology has been designed based on the early estimate of rice grown under the two different varieties. It is envisaged that this methodology would be used for initially attempting a quasi-operational and later an operational mode of assessing areas under the different rice varieties.

\section{Results and discussion}

The different varieties of rice have different durations and morphological differences and are picked up differently by the SAR sensor as is seen from table 2.

Rice crop grows in water logged conditions; however, it can adjust to a wide variety of water regimes (De Dutta 1981; Huke 1982). At transplantation stage, there is standing water which gives low backscatter. As the crop grows, HH backscatter increases steadily in the temporal domain due to an increase in the canopy scatterers till the flowering stage and thereon it stabilizes till the soft dough stage (Chakraborty et al. 1997). Skriver et al. (1999) also reported change in crop backscatter in a multitemporal domain. Thereafter, there is a drop in the $\mathrm{HH}$ backscatter due to the decrease in plant moisture. Figure 1 shows the change in backscatter as observed from different temporal composites. Multifrequency SAR data can be useful in detecting the canopy growth due to the variation in penetration capabilities (Moran et al. 1998). As seen in figure 2 , low values of about -15 to -16
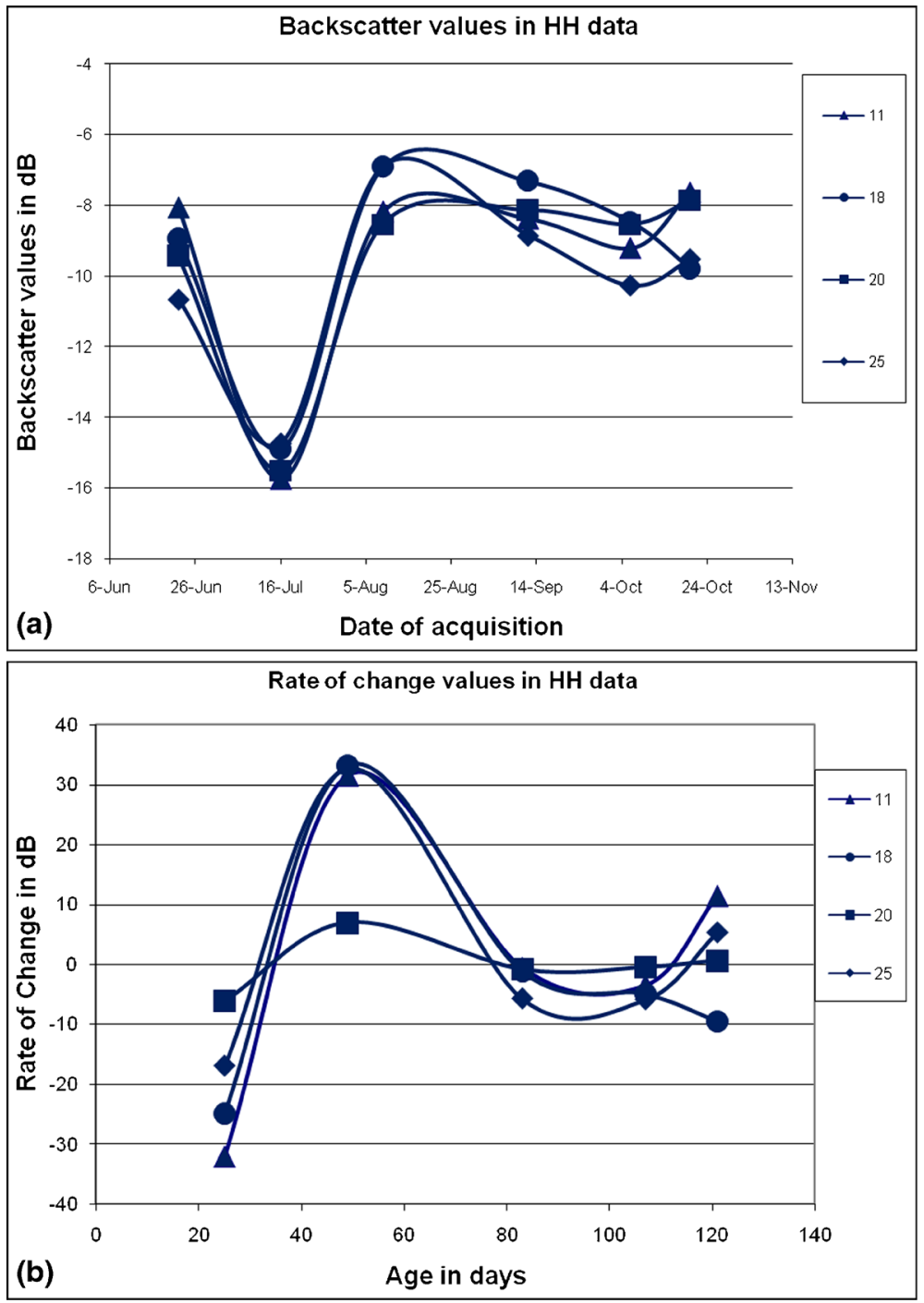

Figure 2. (a) Backscatter values as observed from HH data. (b) Rate of change of backscatter values between consecutive dates. 
$\mathrm{dB}$ in July signify that transplantation was done during that period. The increase in backscatter values to about $-8 \mathrm{~dB}$ in August correspond to vegetative stage. During the flowering to hard dough stages, backscatter values were constant at around -9 to $-10 \mathrm{~dB}$ in months of September and early October. RoC as seen from the figure is high from transplantation to vegetative stage but it becomes constant from flowering to hard dough stage. A slight increase was observed in RoC for maturity stage. Classification based on $\mathrm{HH}$ backscatter values in temporal domain, was done using June, July, August, and September data. This could segregate rice areas with high accuracy (figure 5, left). The rate of change in $\mathrm{HH}$ backscatter was used to segregate the rice areas based on the change in crop morphology. However, this could not improve the discrimination of rice type.
The volume of crop canopy increases as the crop grows. Due to this fact the interaction of crop increases with the incoming polarized radiation (Prevot et al. 1993) and depolarization takes place. To incorporate this fact in the classification model, the behaviour of multi-date $\mathrm{HV}$ data along with its RoC was studied (figure 3). It was observed that at transplantation, the $\mathrm{HV}$ backscatter was about $-23 \mathrm{~dB}$ which increased to about $-19 \mathrm{~dB}$ at vegetative stage. The HV backscatter increased to about $-17 \mathrm{~dB}$ at flowering stage and around $-15 \mathrm{~dB}$ at hard dough stage. The increase in depolarization could be attributed to increasing interactions with canopy as it grows. As seen from the graph, the backscatter decreased by $2 \mathrm{~dB}$ at maturity stage. The same was reflected by RoC graph wherein RoC increased from transplantation to vegetative stage but remained constant till hard dough stage. A
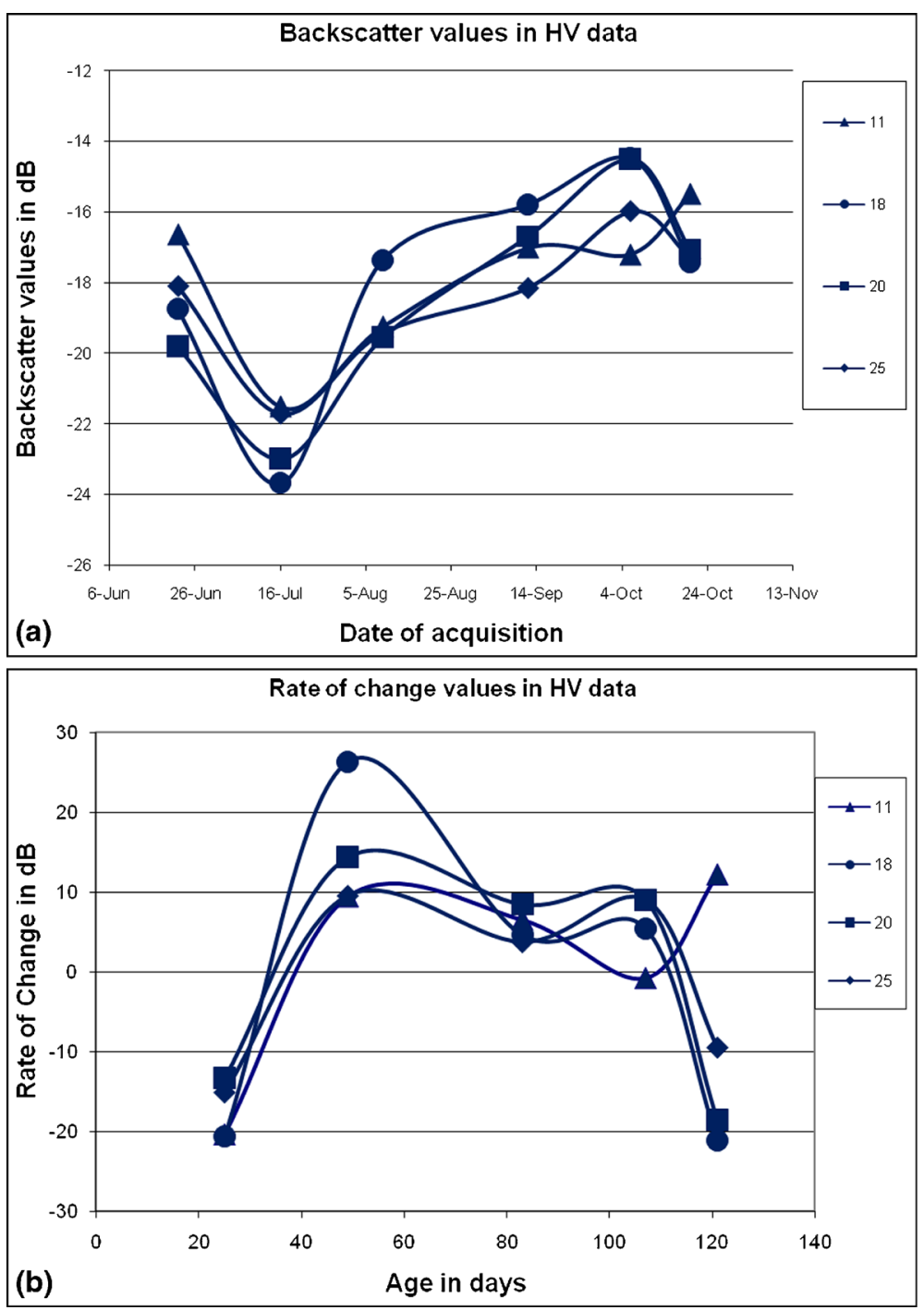

Figure 3. (a) Backscatter values as observed from HV data. (b) Rate of change of backscatter values between consecutive dates. 
slight decrease was seen at maturity stage. This can be attributed to the fact that at maturity stage the canopy moisture reduces causing penetration of microwave inside the plant structure and thereby attenuation. The model formed using $\mathrm{HV}$ behaviour and trend of $\mathrm{RoC}$ of $\mathrm{HV}$ data could not significantly contribute to segregation of different rice types. One reason could be that both the HV backscatter and the RoC taken from consecutive acquisitions did not show significant changes vis-a-vis the crop canopy. These values also picked up other features which exhibited similar trends.

The cross polarisation ratio is a good indicator of crop canopy volume. As indicated by figure 4, the XPR was at about $7 \mathrm{~dB}$ at transplantation which peaked to $11 \mathrm{~dB}$ at vegetative stage. The variation of $\mathrm{RoC}$ was between 9 and $6 \mathrm{~dB}$ at flowering stage and hard dough stage. At maturity, the XPR was around $8 \mathrm{~dB}$. The RoC of XPR showed a similar trend. The use of XPR and RoC of XPR for consecutive dates in model for rice segregation did not give promising results. Similar trend of XPR and its RoC for other features could be a probable reason for this. Therefore RoC of XPR from July to September was used to address the volume component of rice crop as this shows the growth of crop from transplanting to PI/flowering stage. The morphological change contributes significantly to the backscatter and its rate of change. The decision rules were framed using this logic and it was found that the basmati rice could be properly classified. When multitemporal $\mathrm{HH}$ data was used, the staggered transplantation of basmati rice with respect to normal rice was the main reason for crop separability. However, the attempt to confirm the results so that misclassification is ruled out, the RoC of XPR of the basmati crop was used (figure 5, right). The results showed concurrence of about $93 \%$ between the two classification systems.
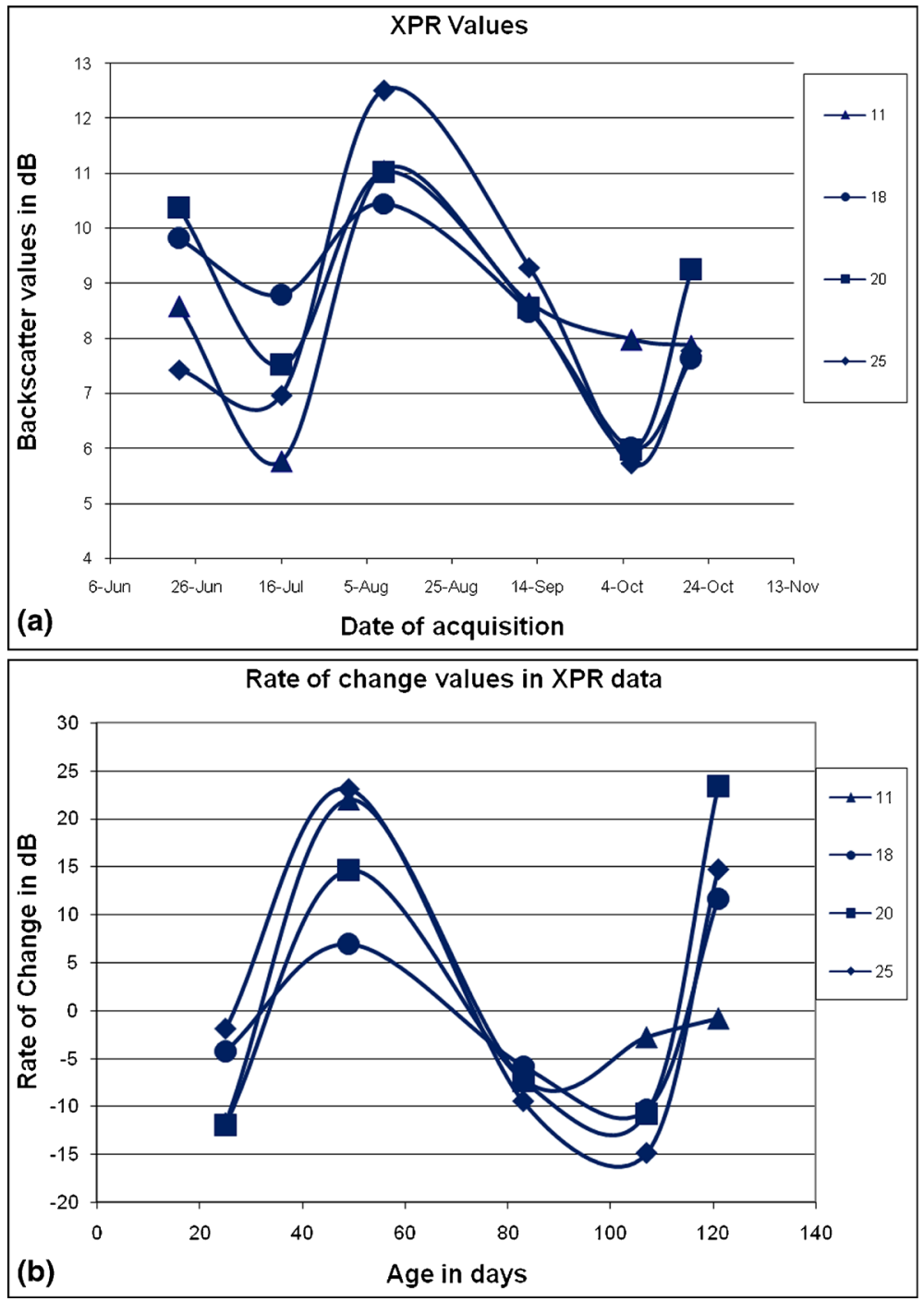

Figure 4. (a) Backscatter values as observed from XPR data. (b) Rate of change of backscatter values between consecutive dates. 
It establishes the fact that the RoC of the crop growth reflects in the RoC of the backscatter when two significant stages are considered. The area estimation under the two different rice varieties was attempted in Amritsar district. The basmati area was estimated at 0.68 lakh hectares and nonbasmati rice was estimated at 1.76 lakh hectares. This was compared with official figures available

(a)
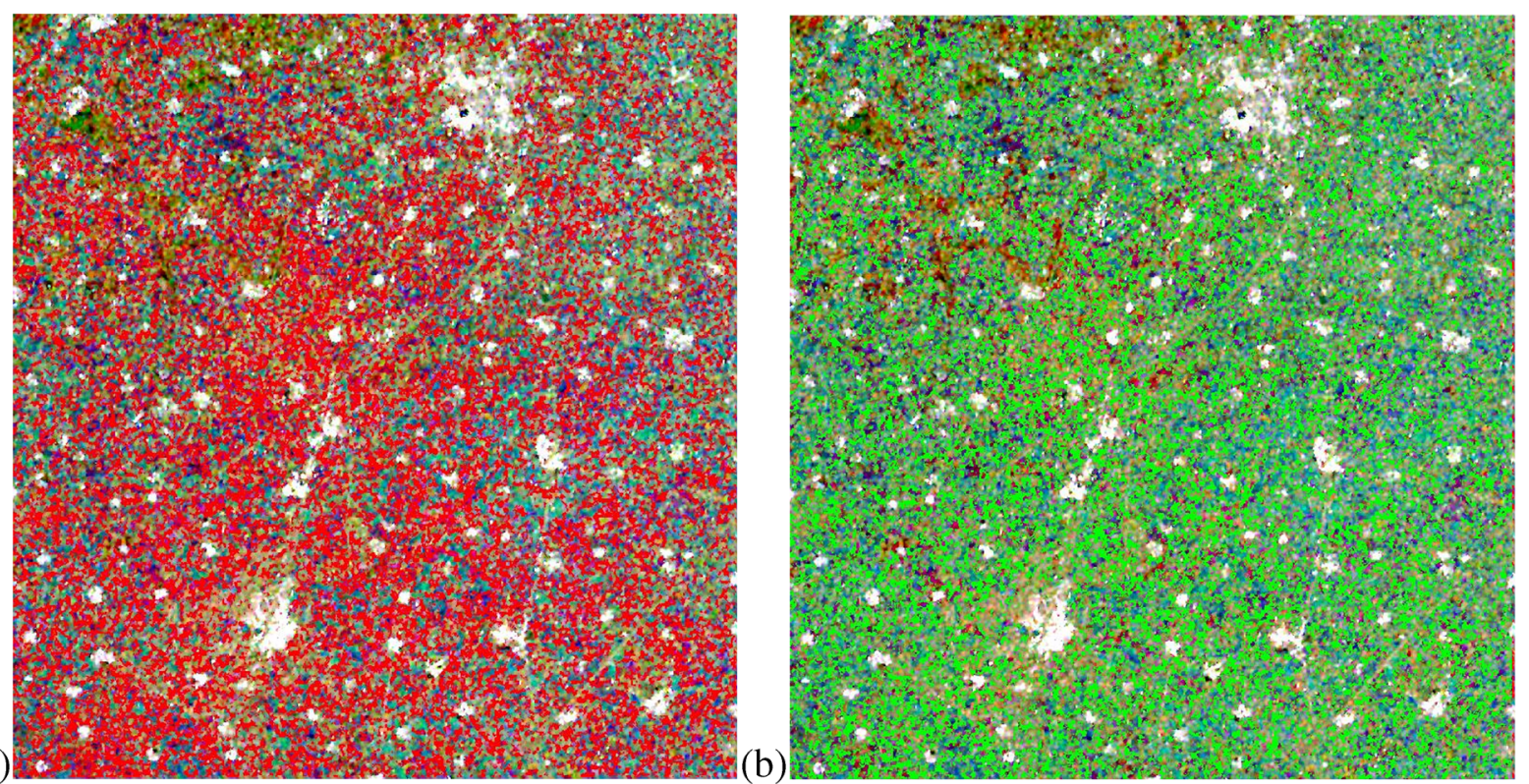

Figure 5. (a) FCC classified using decision rules based on multitemporal HH data of June 22, July 16, August 09 (red areas show rice). (b) FCC classified using RoC of XPR along with decision rules on HH data (green areas show rice). In both the figures, the classified rice pixels (red and green, respectively) have been overlaid on the multitemporal data.

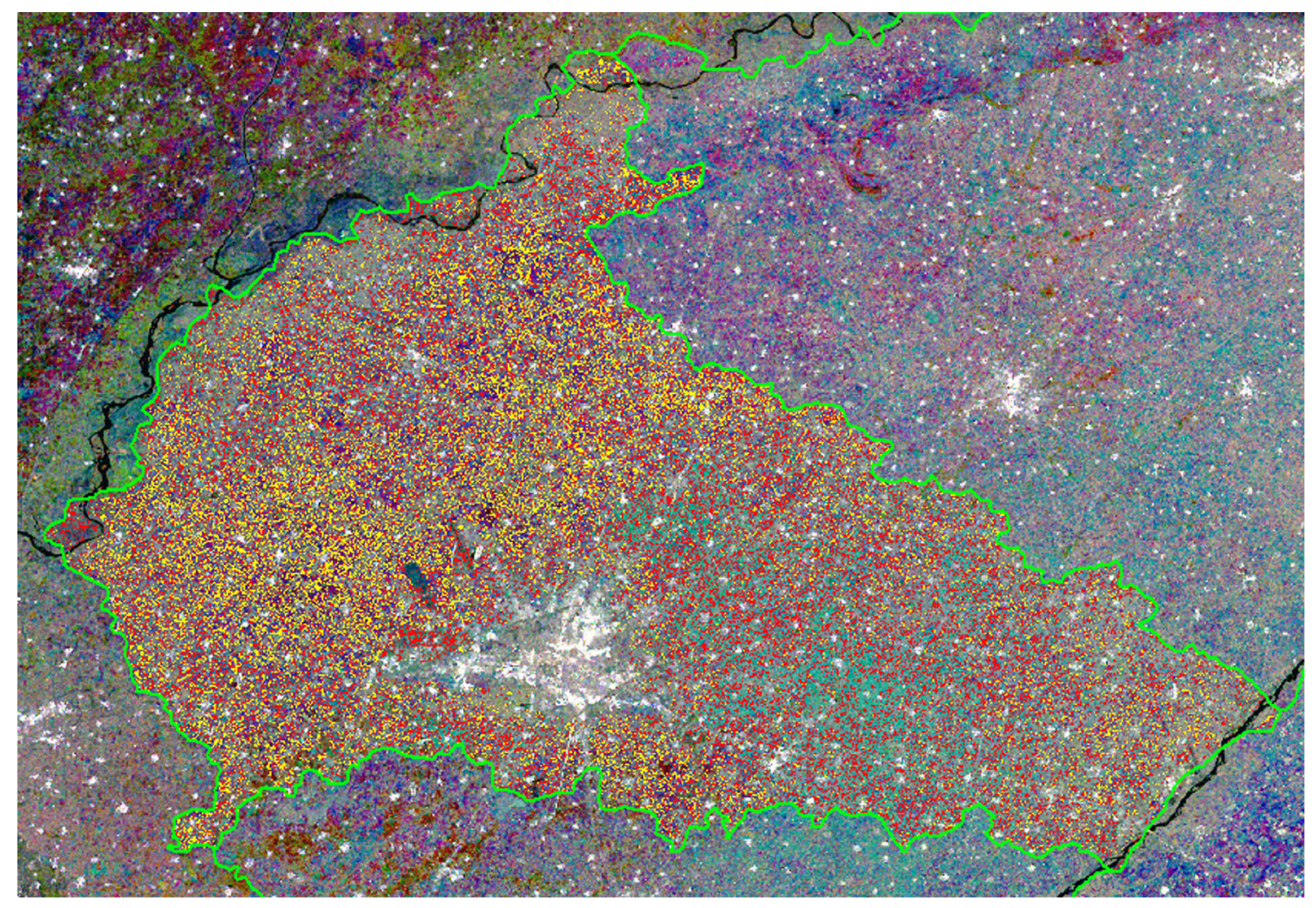

Figure 6. Classified output of Amritsar district overlaid on the FCC of June, July and August acquisitions. The yellow coloured areas show basmati rice and the red coloured areas show non-basmati rice. Amritsar city is seen in white colour. 
Table 3. Confusion matrix generated for the different classes (percent pixels classified under each class).

\begin{tabular}{lrcrrrr}
\hline Feature & Basmati & Non-basmati & Other veg. & Fallow & Urban & Null \\
\hline Basmati & 89.4 & 5.8 & 1.2 & 0 & 0 & 3.6 \\
Non-basmati & 5.1 & 91.2 & 0.7 & 0 & 0 & 3.0 \\
Other veg. & 1.4 & 4.3 & 89.4 & 1.0 & 1.1 & 2.8 \\
Fallow & 0 & 0 & 3.6 & 89.6 & 2.2 & 4.6 \\
Urban & 0 & 0 & 0 & 2.1 & 95.9 & 2.0 \\
\hline
\end{tabular}

from Krishi Vigyan Kendra, Amritsar which reported as Basmati to be 0.6 lakh hectares and non-basmati rice area as 1.83 lakh hectares (http://zpdzone1.org). Figure 6 shows the different rice varieties in Amritsar district.

\section{Conclusion}

Due to the temporal shift in transplantation of basmati rice and its longer duration, it could be separated from normal rice with a high degree of accuracy. The accuracy of classification was about $91 \%$. The confusion matrix in table 3 shows the percent of pixels classified under different classes.

Decision rules formed for segregating rice using the increase in backscatter values from transplantation to flowering stage in $\mathrm{HH}$ temporal domain were applied. Rate of change (RoC) of backscatter values from one stage to consecutive stage were calculated for $\mathrm{HH}$ and $\mathrm{HV}$ data. The use of RoC for $\mathrm{HH}$ data could not contribute significantly to rice classification. HV data and its RoC were envisaged to be used for classifying rice based on its volume component, but models based on them could not give satisfactory results. Cross polarization ratio $(\mathrm{XPR}=\mathrm{HH} / \mathrm{HV})$ along with its $\mathrm{RoC}$ was calculated. There was an overlap of XPR values and the RoC of features other than rice crop which rendered it unsuitable for use in classification. An attempt was made to address the volume component of rice using the XPR RoC from July to September data, i.e., from transplantation stage to flowering stage. The model using this RoC could classify rice areas based on volume.

\section{Acknowledgements}

Authors are thankful to Dr M Chakraborty, Group Director, ATDG/SAC for his technical guidance. The Radarsat data used in this study is due to courtesy of the national project, FASAL.

\section{References}

Ban Y and Howarth P J 1999 Multitemporal ERS1 SAR data for crop classification: A sequential masking approach; Can. J. Remote Sens. 25 438447.

Chakraborty M, Panigrahy S and Sharma S A 1997 Discrimination of rice crop grown under different cultural practices using temporal ERS1 SAR data; ISPRS Photogramm. Remote Sens. 52 183-191.

De Dutta S K 1981 Principles and Practices of Rice Cultivation; Wiley-Interscience, New York, 618p.

Huke R E 1982 Rice Area by Type of Cultural: South, South East and East Asia; International Rice Research Institute, Las Banos, Philippines, 42p.

Moran M S, Vidal A, Troufleau D, Inoue Y and Mitchell T A $1998 \mathrm{Ku}-$ and $\mathrm{C}$-band SAR for discriminating agricultural crop and soil conditions; IEEE Trans. Geosci. Remote Sens. 36 265-272.

Prevot L, Dechambre M, Taconet O, Vidal-Madjar D, Normand M and Galle S 1993 Estimating the characteristics of vegetation canopies with airborne radar measurements; Int. J. Remote Sens. 14 2803-2818.

Saich P and Borgeaud M 2000 Interpreting ERS SAR signatures of agricultural crops in Flevoland 1993-1996; IEEE Trans. Geosci. Remote Sens. 38 651-657.

Skriver H, Svendsen M T and Thomsen A G 1999 Multitemporal C- and L-band polarimetric signatures of crops; IEEE Trans. Geosci. Remote Sens. 37 2413-2429. http:// zpdzone1.org/zone1/download.php?file=Amritsar8780. doc. 